\title{
Selling the selling point
}

\section{How innovation communication creates users of virtual worlds architecture}

Plesner, Ursula; Horst, Maja

Published in:

Convergence: The International Journal of Research into New Media Technologies

DOI:

$10.1177 / 1354856511419915$

Publication date:

2012

Document version

Early version, also known as pre-print

Citation for published version (APA):

Plesner, U., \& Horst, M. (2012). Selling the selling point: How innovation communication creates users of virtual worlds architecture. Convergence: The International Journal of Research into New Media Technologies, 18(1), 49-70. https://doi.org/10.1177/1354856511419915 


\title{
Selling the Selling Point: How Innovation Communication creates Users of Virtual Worlds Architecture
}

\author{
Ursula Plesner \& Maja Horst ${ }^{1}$
}

Keywords: virtual worlds architecture, innovation communication, expectations, users, sociology of technology, interpretative flexibility

\begin{abstract}
This paper explores how Virtual Worlds are rhetorically constructed as obvious, innovative spaces for communication about architecture. It is argued that the marketization of an innovative use of new media platforms happens in early phases of the innovation processes, and the success of new media technologies such as Virtual Worlds hinges on the creation of expectations, which are intertwined with the discursive construction of future users. Drawing on the sociology of expectations and the sociology of technology, the paper argues that configuration of expected users is a central part of the communication about the innovation. It is demonstrated that the creation of markets does not begin when innovations such as Virtual Worlds Architecture are settled, but is intertwined with early expectations about their promises and limitations. Rather than seeing Virtual Worlds as settled and secluded sites for social and cultural innovation in themselves, we have examined how actors involved with them try to sell them as such. A crucial challenge for these actors turns out to be the interpretative flexibility of the innovation, since arguments designed to attract one kind of expected users might problematize the configuration of other types of users.
\end{abstract}

\section{Introduction: The selling point of new virtual spaces for architectural communication}

The aim of this article is to illustrate and discuss how seemingly obvious selling points in relation to new media platforms have to be sold, rhetorically. We analyze how architects try to sell Virtual Worlds as sites for innovative communication about architecture, and point out that a thorough theorizing of innovation communication alerts us to crucial moments in user- and market-making. The empirical background for these observations is a trend towards the creation of new virtual spaces that allow for immersion and online co-creation, in an attempt to innovate in relation to architectural communication. In object-based, three-dimensional, online collaborative spaces, architects can communicate with contractors and other actors about design in new ways. This poses new possibilities of inviting users into the design process. Traditional forms of user involvement in architecture have been constricted by a version of Collingridge's (1980) control dilemma: At the start of the process, prospective users potentially have a large amount of influence, but it is very hard for them to know what to influence, because the architects has

\footnotetext{
${ }^{1}$ This research is part of the Virtual Worlds Project, funded by the Danish Strategic Research Council (KINO) grant no. 09-063261. We would like to thank Bjarke Liboriussen and for his contribution to the production of empirical material.
} 
limited capacity to create models that allow users to imagine the proposed environments. In contrast, object-based virtual worlds promise a technology which affords elaborate models of buildings or cityscapes, while being very flexible and open to change. For those architects who can be seen as first movers (Rogers 1995) in relation to virtual worlds as a professional communication platform, this seems like a real selling point for virtual worlds technologies. Users of architecture can be invited to test, inhibit and co-create new physical environments in an immersive way - in what has been termed a process of imaginative inhabitation (Rice 2007). A positive outcome of user-involvement is taken for granted as a way of democratizing (von Hippel 2005) architecture, and users are expected to jump at this possibility for exercising user-driven, or at least userinvolving innovation in physical space. Critiques of this idealized view of user-involvement in architecture have been raised (Pallasmaa 2005), but this paper will not take a normative stand in relation to this debate. Instead, we are interested in pursuing how articulations of 'the selling point' of Virtual Worlds Architecture are intricately linked to specific imaginations of users. Drawing upon the STS literature on innovation and particularly on the configuration of users (Grint \& Woolgar 1997; Oudshoorn \& Pinch 2005; Akrich 1994), we assume that a user is not a preexisting entity waiting to be mobilized by the architect. Rather, the architect has to devote time and effort in order to create interest and configure prospective users during the design process. The argument in this paper is that such configuration work can be understood as a crucial form of innovation communication, which is central to the ability to make an innovation.

The theoretical contribution of the paper is the proposal of an alternative to traditional perceptions of innovation communication (Rogers 1995), which portrays communication about an innovation as an add-on to the design phase, that is, as something disconnected in time and place from the design of the innovation. As an alternative, we want to explore how communication is an integral part of the innovation process. We are inspired by Pinch (2003), who argues that salesmen are an overlooked, but important, part of early technological development processes. In this paper, we follow his suggestion to study 'selling as an activity' (Pinch 2003: 269). We do, however, not focus on the human actors called 'sales people', but rather on selling as a function, which is part of the entire process of innovation. Our claim is that innovators are involved in the 'selling' of an innovation as soon as they begin to imagine the prospective users and make arguments about why these users should let themselves be convinced that the innovation is beneficial.

In the following section, we outline the theoretical argument on innovation communication as the simultaneous shaping of expectations to future solutions and the configuration of prospective users. Subsequently, we turn to our empirical case and analyze how the promise of virtual worlds for architectural communication (or Virtual Worlds Architecture, as we will call this innovation in the making) is articulated among architects and users of Second Life (SL) for architectural representations. On the basis of this material, we identify three central arguments for using virtual worlds to communicate about architecture. We call these the 'ahead of the pack' argument, the 'revelation' argument, and the 'open innovation' argument, and we have structured the first part of the analysis into sections which discuss each of these in turn. In the first section we see how SL is constructed as the place to be if you want to position yourself as cutting edge. And with this comes a view of users as demanding, tech savvy audiences which are already 'out there'. In the second, we see how SL is constructed as a way to minimize the gap between an architect with spatial imagination and users without such. Users, here, are constructed as needing help from the communication technology, because it can reveal otherwise hidden (spatial) issues which are of 
crucial importance. In the third section, we see how SL is constructed as a means to tap into a pool of resources from various specialists. In this argument, users appear as progressive, sharing and open innovation minded.

In the empirical material, we also identify articulations of resistance to each of these arguments. This prompts us to reflect upon the work required to 'sell the selling point' of virtual worlds as obvious sites for communicating about architecture, and we have devoted the last part of the analysis to the illustration of three different types of resistance. On this basis, we end the paper with a discussion of the challenges inherent to innovation communication. In particular, we focus on the way in which arguments, which are designed to enroll one type of user, can be seen as obstacles to the enrollment of other users. Hereby we also question the positive aspects of interpretative flexibility implied in the early studies of user configuration.

\section{Theorizing innovation communication and user expectations}

In his seminal work on the diffusion of innovations (Rogers 1995), Rogers' central concern is how and why users adopt a technology, and communication is seen as a central medium through which the diffusion process takes place. From the point of view of Actor-Network-Theory (ANT), Bruno Latour (1986) has criticized this perspective, arguing that an innovation is not a stable object, endowed with a certain set of characteristics that will be more or less convincing to potential users. Rather, early ANT studies (e.g. Law 1991) were founded on the conceptualization of technological innovation as a process of translation, in which actors were enrolled on the basis of their own interests. Actors would become engaged with an innovation if they could use it to further their own ends, but these objectives did not need to be similar to the original aims of the innovators. The model of translation therefore, does not understand communication as a stable intermediary through which the innovation is brought to the attention of adaptors. Rather, communication is part and parcel of the development of the innovation, because the formation of networks and 'interessement' of actors is part of the innovation process itself. However, ANTstudies have primarily been engaged in the study of the process of innovation and the formation of socio-technical networks and have not considered the aspect of communication in any depth. This paper places emphasis on the communication aspect, and we define innovation communication as an integral part of the innovation processes which aims at generating support for the development of an innovation into a stable part of the socio-material reality.

Inspired by ANT, a number of scholars have focused on the performative role of visions and expectations in the innovation process (van Lente and Rip 1998; Brown, Rappert, \& Webster 2000; Brown \& Michael 2003; van Lente 1993). According to this literature, the central aspect of a study of expectations is not whether they are justified and will become true in the future, but rather how they serve as justifications for actions in the present. Actors routinely base their decisions on anticipations about future states of affairs, and communication about expectations is therefore a central component of the development of innovations. In order to gain support, build networks and enroll actors in support of the innovation, innovators have to engage in visionary communication. This is what Pinch alluded to when he claimed that sales people are the missing masses of technological development (Pinch 2003). In the present paper, we want to follow this line of argument by focusing specifically on the creation of expectations about how Virtual Worlds Architecture will be beneficial to prospective users. In our view, this form of creation of user expectations - which should be understood in its double meaning of expectations by and of users 
- is a crucial element of innovation communication. In this way we seek to extend the application of the sociology of expectations to the field of communication as such, and argue that communication about the future is a general strategic form of communication, which innovation actors engage in routinely.

Steve Woolgar (1991) and Madeleine Akrich (1994) have suggested that we adopt a semiotic perspective and investigate how designers of technology 'configure the user' (Woolgar 1991) by prescribing a certain role and context for use as an integrated part of the entire process of technological development (Oudshoorn, Rommes \& Stienstra 2004: 31). In the words of Akrich, designers

...define actors with specific tastes, competences, motives, aspirations, political prejudices, and the rest, and they assume that morality, technology, science, and economy will evolve in particular ways. A large part of the work of innovators is that of "inscribing" this vision of (or prediction about) the world in the technical content of the new object. I will call the end product of this work a "script" or a "scenario" (Akrich 1994; 208)

Akrich and Latour also suggested the concept 'program of action' to describe how technology is designed to prescribe the actions of users and other actors. 'Anti-programs', then, describe programs of actions which are in conflict with the program chosen as point of observation (Akrich \& Latour 1992: 261). This is important in relation to our case, because the development of Virtual Worlds Architecture is still at an early stage, which means that there is a lot of 'interpretative flexibility' with regard to the meaning of the innovation (Pinch \& Bijker 1984). Currently, there is no stable interpretation of what the innovation is or should be. Thus, we can say that entrepreneurs of Virtual Worlds Architecture have competing visions about the innovation's program of action and these conflicting expectations can function as anti-programs to each other.

The concept of script has been employed to study the relationship between the imagined user and the real users when the technology is implemented (e.g. Lindsay 2003; Oudshoorn 2003). In the present paper, we are not interested in this relationship, but rather in the way the imagined user is configured or scripted in the communication about the innovation. The idea is that the entrepreneurs of Virtual Worlds Architecture configure use and users through their efforts to sell their vision of the innovation and enroll actors in its 'program of action'. An imagined user is coconstructed with the rest of the program of action of the technology, and this form of innovation communication has consequences for the further development and the viability of the visions of future technological solutions. To paraphrase Oudshoorn, technologies will only become successful if technological innovators configure identities of users in a way that will inspire future users to perform these identities (Oudshoorn 2003: 210). In our case, however, the crucial thing is that there is a lot of interpretative flexibility with regard to these future users, so entrepreneurs of Virtual Worlds Architecture compete with each other about the creation of the most plausible vision.

It has been argued that designers use a number of different inputs for imagining the user, although they are rarely explicit about how they generate and integrate these representations into their designs (Akrich 1995; Hyysalo 2006). Schot and de la Bruhéze (2003) reminds us that 
...in management studies an accepted lesson is that most product innovations fail because of a lack of understanding of users' needs. At the same time, it is also clear that such an understanding is hard to get; a merely increasing emphasis on market research itself does not lead to a better understanding and a higher probability of product success. Designers do not seem to seek relevant market information; even when they do, they often neglect relevant market information. (Schot \& de la Bruhéze, 2003: 231)

In our perspective, the problem is not so much that designers or entrepreneurs do not seek to understand the user, but that there is no ready-made user to understand. An imagined user is a construct in the complex set of relations of expectations and socio-technical possibilities that constitute the innovation communication about Virtual Worlds Architecture. 'Understanding', or configuring, the needs of this imagined user is therefore a complex process, given that any change in the network of expectations might change the configuration of the user. Furthermore, the large interpretative flexibility and the competing visions about Virtual Worlds Architecture imply that there is not just one imagined user. In addition, it is not just designers, who imagine users. As Lindsay has argued, many actors involved in the process will imagine users and contexts for use:

I propose that "user representations" encompass many other imagined users, and that these user constructions are not built, and do not exist, in isolation. Each of the social groups involved with a technology throughout its life history, even those that are not directly involved, will have its own ideas about who and what the user is (Lindsay 2003: 32)

\section{The challenge of interpretative flexibility}

Innovators thus find themselves in a complex landscape of user representations, each of which relates to a specific interpretation of the technological innovation. For innovators, this interpretative flexibility serves as a potential problem, as well as a potential resource as they struggle to gain support for their own specific vision of the innovation. In so far as the interpretative flexibility works against stabilization of a technology, it may be problematic. In an analysis of innovation in WHO, van Kammen (2003) demonstrates how innovators face serious problems because their definition of 'worldwide users' is so unspecific that the interpretation of the innovation keeps changing. The simultaneous lack of stability in user configuration and technological vision reinforces each other and prevents stabilization of the innovation. In contrast to van Kammen's example, interpretative flexibility can also be seen as a resource, because it allows different types of actors to have an interest in the innovation. With a semiotic approach, Woolgar analyzes the development of a new technology as text, and argues that the "text sells well if many different readers find a use for it. One might even go so far as to say that an author's attempts to prescribe readings, to delimit ways in which the text can be read, is a sure recipe for disaster" (Woolgar 1991;73). According to Woolgar, it is in the interest of innovators to avoid a strict and narrow definition of the user of a technology, because this will delimit the number of actors prepared to be inscribed in its program of action. A user configuration which restricts the range of possible readings will not generate success.

According to Bijker \& Pinch, interpretative flexibility is an integral part of the development of a new technology. Interpretative flexibility will be high in the early stages of an innovative process, but will decrease in accordance with the stabilization of the technology into a specific socio- 
material artifact (Bijker \& Pinch 1984). In the present paper, we will deal with 'interpretative flexibility' as something that poses a dilemma for innovators. Our study of Virtual Worlds Architecture takes place at a time without a clear trajectory for the development of the innovation, and, put crudely, innovators face the problem of whether they should seek to join or beat competing programs of action when they try to recruit users through innovation communication. It is one thing for social scientists to notice that interpretative flexibility diminishes as the innovation becomes more stable and entrenched into particular socio-technical networks. It is quite another thing for innovators to be in the midst of this flexibility and try to communicate productively in order to further their own program of action. In the present paper we focus on this strategic challenge.

\section{Empirical material and methods: Through a community of first movers and early adapters}

Innovative ways of communicating about spatial matters is nothing new to architects. They have access to a range of information and communication technologies through which they communicate design visions with other actors throughout the building process. Besides using paper and pencils, they produce auto-CAD drawings, foam models, cardboard models, fly-through illustrations, and other forms of visualization (Ewenstein \& Whyte, 2009; Gänshirt, 2007; Yaneva, 2009). In practice, a lot of these technologies co-exist, and are continually combined with various emerging ICTs in an ad hoc fashion. Elsewhere, we have described how experiments with Virtual Worlds Architecture take place on various new media platforms (Plesner 2010; Plesner \& Horst 2010). In this paper, we focus on activities relating to the online 3D social world, Second Life (SL), which we consider one type of innovation in the making, competing with other Information and Communication Technologies within the above described professional domain.

The point of entry into the empirical material was a rather close community of SL residents who often meet to discuss or experiment with architecture. This community came to our attention via the participation of two very active members in the online live debate show in SL, Metanomics ${ }^{2}$, where they were interviewed about their experiences with, and opinion of, the use of Second Life for purposes of communicating about architecture. We conducted interviews with these two residents, and they helped establish links to corporations and institutions, as well as interview appointments with people experimenting with architecture in Second Life. This paper is partly based on interviews, partly based on material available at blogs and web pages, where SL is sought sold - both conceptually and economically - as a relevant place for working with architecture. The blogs were chosen because, through technical discussions and the mentioning of new projects, they articulate the promises and shortcomings of virtual worlds for use in architecture. Some of the interesting blogs which deal exclusively with virtual worlds were 'Archvirtual.com', 'Primpushers', 'Metaversically Speaking', and 'Learning Inworld'. Other blogs belonged to users who experimented with virtual worlds in connection to actual construction projects, for instance that of University of West Australia. Some web pages belong to architectural companies that are driving forces in promoting SL for use in architecture (Crescendo Design and David Denton AIA), and some belong to companies that experiment with using virtual worlds in this way (Dedato designers and architects, Anche Chung Studios, Open Architecture Network, Hometta, Open Neighborhood, Queens Community Board, Coldwell Banker, Starwood Hotels). Interviews were

\footnotetext{
${ }^{2}$ http://www.metanomics.net/show/archive111708/
} 
conducted with 10 of the people involved in the projects discussed in these blogs and presented on these web pages.

Because we deal with innovators' attempts to establish new programs of action, we do not consider it a methodological problem to enter this community via strong actors, and get connected to their network. On the contrary, given the nature of social media, this reflects how communities are build, and it enriches our study to follow the ways in which they link to one another, promote each other, and co-produce the hyping of possibilities and expectations to Second Life.

The research was conducted from late 2009 to late 2010, but also includes reports on some of the early experiments with SL, because they are still drawn into discussions in the community and serve as examples. This entails that the material both expresses some of the very early articulations of expectations to Second Life, and some of the later discussions of how Second Life is only one medium among others, and might benefit from 'cross-breeding' with those. We collected the material with the ambition of exploring how central actors articulate the selling point of SL, and we searched the material for articulations of promises and problems related to its usefulness for users of architectural communication. Much in line with Wilkie and Michael (2009), we have a focus on rhetorical patterns in accounts about virtual worlds architecture, with a particular interest in arguments concerning expectations about future use and future users. In the present context, an argument is defined as a discursive entity, which constructs a particular relation between problems and solutions in the effort to make an audience adhere to a particular representation of a situation (Horst 2010; Perelman \& Olbrechts-Tyteca 1969). An argument is a prescription of how Virtual Worlds Architecture should work as a solution.

We have coded interviews, webpage texts and blog texts systematically with a focus on articulations of problems/solutions. On the basis of the coded material, we have had an inductive approach to the structuring of the material into three types of arguments that can be said to make up important programs of action. In the material, it was obvious that solutions were also problematized. The second half of the empirical analysis is therefore devoted to the analysis of anti-programs. This is not to suggest that the different programs and anti-programs are always easily distinguishable from each other, or always stand in clear-cut opposition to each other. In our understanding, ANT's image of programs and anti-programs standing in front of each other, moving back and forth depending on the strength of their respective alliances, need to be softened by an analytical focus on the interpretative flexibility which allows for programs and antiprograms to take many forms. We will return to this discussion in the conclusion.

\section{Articulating the selling point}

Throughout the diverse empirical resources described above, we find that the use of SL for architectural design is promoted through roughly three different sets of arguments which create expectations of users in different ways. The first constructs SL as the place to be if you want to position yourself as cutting edge. The second constructs $S L$ as a way to minimize the gap between an architect with spatial imagination and users without such skills. The third constructs SL as a means to tap into a pool of resources from various specialists. We will go through each of these sets of arguments in the following, discussing how each configures particular types of users.

\section{The ahead of the pack argument}


For some corporations using SL for the purpose of communicating about architecture, the rationale for doing so is constructed as a way of addressing the needs and wants of a technology savvy audience, which is supposedly already 'out there'. Using SL becomes a way of catering to a sophisticated audience in an effort to create a distinguished business strategy. For instance, as Starwood Hotels launches Aloft, a second life hotel to be realized physically, they talk about "directing itself towards the new generation of travellers" ${ }^{3}$. And Coldwell Banker, a company using SL to market homes for sale, talk about "an entirely new pool of potential customers who embrace technology and collaboration" ${ }^{4}$. In this type of communication, the selling point of SL is its cutting edge way of exposing spatial matters, and the promise that such a virtual world platform allows various users who are 'ahead of the pack' to interact. This argument was typical in the early SL days, around 2007. Anyone who was present here would signal innovative communication and an ability to adjust in relation to audiences who were expected to have embraced this new communication platform.

What needs to be sold - economically - in these examples is not the virtual world representational 'service', but the company brand created by being present here, and - on longer terms - the products of this company. The 'add on' is free for users - an aspect which is clearly expressed in the case of the company Hometta. Hometta wants to present a virtual neighborhood to future buyers of real life houses. In this way, buyers can virtually explore real life architecture. Hometta is not creating a market within a virtual world and they do not talk about users as clients - users are called fans:

We call it H-Town. Above all else, H-Town will help Hometta fans - and their family, friends and building professionals - further experience the Hometta designs in an interactive and exciting way. Through avatars, visitors will be able to explore, socialize with others through chat, and participate in self-guided tours of the Hometta houses. [...] And did we mention it's free? ${ }^{5}$

The virtual world functions as a service integrated with real life practices, and will be paid for through actual construction projects - but Hometta still has to convince users that it is worthwhile spending time on. They do this through referring to the interactive, open, and social element of $\mathrm{H}$ TOWN, and through stressing that there is no extra cost attached to this service. They construct their company as meeting the demands of future users who expect the use of interactive, exploratory and social media.

The image of the tech-savvy audience is backed up with an opposition created between more conventionally minded people and 'more advanced', demanding users, who can expect this new media technology to allow them feel more at ease with like-minded people. Interestingly, the argument includes a reference to the promise of 'being seen' (through your avatar), presumably as

\footnotetext{
${ }^{3}$ Promotion video: http://www.youtube.com/watch?v=3SZoEYipxDU\&feature=player embedded\# Accessed 30 Mar 2010

${ }^{4}$ Coldwell Banker press release, 2 Aug 2007

http://www.coldwellbanker.com/servlet/News?action=viewNewsltem\&contentld=1319220\&customerType=News.
} Accessed 1 Apr 2010

${ }^{5}$ http://www.hometta.com/content/h-town-preview. Accessed 30 Mar 2010 
an advanced, sophisticated user. In a celebratory blog post about the $\mathrm{H}$-town project, it goes like this:

If you've ever tried to build a house that isn't 'normal' in every way, you're already acutely aware of the push-back heard from builders, real estate agents, neighbors, and even friends and family. There's an enormous pressure to conform, and the fear factor can be overwhelming [...] At H-Town, you will soon be able to gather the resources you'll need, meet other like-minded people, and share your experiences or fears - which could be exactly what this new direction in residential design needs - a virtual support group, and a place to go and get inspired [...]Rather than flipping through the pages of a magazine, or browsing a website as a passive observer, $\mathrm{H}$ Town gives you a presence - a place where you can see and be seen ${ }^{6}$

Related to this argument is the construction of yet another vision for users, namely the chance to develop new relationships through this new site for collaboration. The imagined future users, here, belong to a global elite of professionals. For instance, Dutch Match was en event meant to promote closer business cooperation between Dutch and South African designers. At the time, Peter van Dijk of Dedato (an architectural company in Amsterdam) held that

Our newest exciting project is in the virtual world of Second life and truly brings all our disciplines together where our architects become internet designers. For this project we are looking forward to meet South African architecture agencies and interactive media design agencies. The Dedato design lab in Second Life could be our mutual workspace ${ }^{7}$

The same type of articulation is seen in a specific project carried out by the Open Architecture Network, where it is suggested that the virtual worlds platform might put the global design team of the willing into contact with other passionate users of Virtual Worlds Architecture:

As an optional extension of our entry, we suggest the possibility of considering our team your 'tele-architecture' team, whereby the people who actually build and use this facility will be given access to a brilliant and diverse global community of members who are equally passionate about this cause. ${ }^{8}$

When talking about global collaboration, the crucial point is that the new ways of collaborating across geographically dispersed places is seen as a progressive challenge to the traditional feature of architecture as bound to a geographical space. Note also that global is per definition positive, because it gives access to diverse actors, who can contribute to the creative process. 'Passionate about the cause' in this case function as a description of the frontrunners of the innovation, and their passion is a key resource for the innovative process. In this way, the program of action described in these arguments has similarities with our third group of arguments about open innovation described further below.

\footnotetext{
${ }^{6}$ http://archvirtual.com/?p=2456. Accessed 31 Mar 2010

7 http://www.dutchmatch.co.za/dedato.html. Accessed 30 Mar 2010

${ }^{8}$ http://openarchitecturenetwork.org/node/1434. Accessed 31 Mar 2010
} 


\section{The revelation argument}

$\mathrm{SL}$ is also constructed as a solution to the problem of non-architects not being able to understand traditional means of communicating architecture. As it is said about the promises of SL on the Crescendo Design webpage,

If you can't visualize what the home will look like by reviewing 2D plans and elevations, request or hire someone to sketch or illustrate your home in 3D. [...] Consider the cost of this service on balance with the risk of investing hundreds of thousands of dollars in a home that might look odd (it happens all the time!) $)^{9}$ To me, this is so much closer to the way we actually experience architecture in the real world, and represents the future of every kind of online architectural resource. Looking at a picture of a house is great, but experiencing a house in an immersive, realtime environment alongside others is much better ${ }^{10}$

When SL is sold in this way, it happens though comparison with the insufficient, difficult to understand, traditional means of communicating architecture. Architect David Denton, who designed a shopping mall in SL for a client based in Cairo, tells a similar story to present SL as a necessary answer to customers' difficulties of understanding space:

Initially I built the space in $3 d$ max and produced several renderings that I showed to the client. The client seemed to have difficulty understanding the space, as I had to admit, I myself was experiencing too. [...] This project needed to be experienced dynamically by moving through the space [so I decided, now is the time to try SL as a design tool]. Fortunately, the client had recently heard about the possibilities in the virtual world and had been told he could put his products (ceramics such as bathroom fixtures and tiles) into a virtual world catalog. This discussion led to an agreement to try $S L$ as a design tool for the project ${ }^{11}$.

With the expression 'the project 'needed to be' experienced in a more illuminating way, Denton indicates that the promise of the medium is of such a kind that architects and clients simply must jump at this new possibility. Having succeeded in selling the selling point to clients, Denton is also able to tell stories which focus on moments of revelation of clients - i.e. the moments where clients really come to share architects' idea of SL's selling point. In a 2009 interview, he describes a client's reaction as follows: "he said to me, when he pointed to the screen: this does not lie" ${ }^{12}$. In a 2010 interview with us, he explained how

... when we presented the project to the client we had a set of floor plans ready in case he wanted to see them, but we didn't draw sections or elevations. We didn't do what one normally does in a presentation. We just walked in and showed this model. [...] It

\footnotetext{
${ }^{9}$ http://crescendodesign.com/?cat=8 Accessed 29 Mar 2010

10 http://archvirtual.com/?p=2456. Accessed 31 Mar 2010 (comment on Hometta by Crescendo Design owner Jon Brouchoud)

${ }^{11}$ http://archvirtual.com/?p=1153 (Interview with David Denton) Accessed 29 Mar 2010

12 http://reflectionsegypt.ning.com/page/practices-1 Accessed 29 Mar 2010
} 
was a big success. We presented it to the client. He got it. He understood it. He loved it."13

The architect himself had a similar kind of revelation, and "cannot imagine designing a building in any other way now" ${ }^{14}$ This story constructs SL as actually fulfilling the promises of SL, by solving some of traditional architecture's communication problems. It also engages with the issue of SL's relation to 'reality' by arguing that such spatial communication does not lie. The user, in the vision supported by this argument, is liberated from the misunderstandings and possible deception related to the problem of being non-professional.

In this argument, users are in need of the architect's assistance. The user in need of assistance, however, can be imagined as more or less active in the design process. At the homepage of Crescendo Design, possible clients are promised an active role in the design phase:

During virtual meetings, we can test different design ideas in 'real time' - meaning the changes we make appear on your screen immediately as they're made. Clients and builders can even learn the simple building tools and make their own suggestions. The virtual model works great for testing out material choices, paint colors and eventually even landscaping options and furniture layouts ${ }^{15}$.

Users, it seems, have to be constructed as capable of using virtual worlds for architectural design, even if they are not tech savvy. It testifies to its interpretative flexibility that Virtual Worlds Architecture is supposed to cater to both technologically capable and incapable users - the innovation is expected to be useful on various levels, and demanding varying degree of expertise from users.

\section{The open innovation argument}

Another way of articulating the selling point is to establish SL as an obvious site for democratizing architecture, because actors other than architects are able to influence the early phase of a design project. This is closely linked to arguments regarding open innovation, where architecture may benefit from the creative potential of co-creation by a variety of actors.

Wisconsin-based architect Jon Brouchoud is among the most active promoters of "public involvement" and "user-generated architecture". The vision expressed on the company's home page says: "This could really make architecture so much more participatory when you can literally occupy buildings together before you break ground". The home page also contains critical statements about traditional architecture, pointing out that it "places so much emphasis on the hero architect that creates signature designs or masterpieces. In fact, that represents such a tiny fraction of what our cities really consist of ${ }^{16}$. The arguments are framed within a vocabulary of rights, and thus construct SL as a democratic medium. It addresses its customers with the

\footnotetext{
${ }^{13}$ Interview by UP, 30.1.2010

${ }^{14}$ http://www.youtube.com/watch?v=SP1vr3zSVCE. Accessed 29 Mar 2010

15 http://crescendodesign.com/?cat=8. Accessed 29 Mar 2010

16 http://crescendodesign.com/?p=390. Accessed 29 Mar 2010
} 
statement: "it is your right to have a clear picture of what it is that you are investing in"17. These types of statements construct SL as the obvious choice of new communication technology for honoring the rights of users. When SL is constructed as a tool for participatory communication, users are constructed as being demanding and interested in participation. An example of this can be found in the description of the H-TOWN project, which refers to SL as meeting the perceived demands of future, demanding users:

As it becomes easier to import architectural CAD and BIM models in the months and years ahead, I think anyone building new construction will rightfully come to expect this kind of immersive visualization - and Hometta will clearly have a head start in providing some of the most advanced, interactive virtual experiences available online. But there's so much more to it than visualization. Hometta is as much a community and resource for anyone interested in smarter houses as it is a place to buy blueprints. By offering their community a place to meet each other in a realtime, immersive environment, staged within a contextual framework of smart, modern houses, they're leveraging $\mathrm{H}$-Town as a 'place' or a catalyst toward instigating crosscultural exchanges about residential efficiency and what 'house' means throughout the world. ${ }^{18}$

The vocabulary of democratic engagement ('rightfully', 'community', 'public', 'grassroots') is circulating in various presentations of the meeting of Second Life and real world construction projects, as in a project where SL was used to build a replica of a project building site. This project was created by

.... an open and public community of over 40 contributors from around the world representing a wide range of disciplines and backgrounds. To facilitate this effort in design collaboration, we developed a grassroots '3D-Wiki' technology that is built on the virtual reality platform: Second Life.

In another city planning project, Second Life is similarly constructed as a site for collaborative design, and as coupled to democracy projects. Queens Community Board reports how New York Law School purchased an island in $\mathrm{SL}^{19}$, to give people of the local community a chance to influence the design of a local park. They sell the Landing Lights Island in the following way: "In true wiki fashion, you will also be able to call up and edit other people's models of the park. The design project will interface with a democracy project that will select and promote a winning design, with a prospect that the design will actually get built!" ${ }^{20}$ Users, in these visions, have to possess some design skills that can be employed in an online setting"21 In such articulations, focus is slightly removed from the innovative dimension of Virtual Worlds in relation to architecture, to emphasize their participatory potential more generally. Users, here, are then constructed as active citizens, engaged in local development projects or cultural heritage project (with a spatial

\footnotetext{
${ }^{17}$ http://crescendodesign.com/?cat=8 Accessed 29 Mar 2010

18 http://archvirtual.com/?p=2456. Accessed 31 Mar 2010 (comment on Hometta by Crescendo Design owner Jon Brouchoud)

${ }^{19}$ http://www.cb3qn.nyc.gov/page/LLP/. Accessed 31 Mar 2010

20 http://democracyisland.pbworks.com/Landing\%20Lights\%20lsland. Accessed 31 Mar 2010

${ }^{21}$ http://openarchitecturenetwork.org/node/1434. Accessed 31 Mar 2010
} 
dimension). And Virtual Worlds become the means to achieving participatory 'wiki' formats of public engagement.

A particular version of the argument is to stress that $\mathrm{SL}$ is the obvious place to collaborate creatively, a construction which establishes users as capable and talented - a pool of resources to be pulled together. Visions of collaborative spatial design are obviously shared by actors who are not architects or builders. For instance, when the Tech Virtual used SL for prototyping real world museum exhibits, this open innovation ambition was central:

...the Gordon and Betty Moore Foundation funded this idea in 2007 [...]. Basically they asked, what if you could use Second Life to prototype exhibits with simultaneous input from experts and casual visitors as well? It opens up the creative process to a much wider talent base, and means that you can preview ideas before you ever even order any materials. It's the open source method of development, applied to exhibits" ${ }^{\prime 22}$

In a similar way, University of West Australia constructs SL as a site for creative explorations, where users' contributions may result in innovative architecture. They have called for contributions to the so-called Flagship Challenge, an architecture competition in SL which should result in the design of "a building that captures the essence of creative engagement, which could possibly be built" ${ }^{\prime 23}$. Such visions presuppose a huge mass of creative potential among users who are 'out there', a potential which can be harnessed through Virtual Worlds Architecture. The innovation appears as easily accessible, also to 'casual visitors' without technical expertise in relation to VWs.

\section{Overcoming resistance - working harder to sell the selling point}

The three identified types of argumentation for using SL in architecture can all contribute to strengthen each other, because they give different types of users different reasons for adopting the suggested innovative communication form. According to Woolgar (1991), the existence of overlapping storylines around an innovation should increase the chance of it being taken up. As such their differences should be an advantage and their co-existence should help the innovation spread. However, as our analysis will demonstrate, this notion begins to appear problematic when we look at the different types of resistance to the adoption of SL and how these instances of resistance are interpreted and give rise to efforts to overcome them. Meeting one form of resistance might very well mean that another is enforced. In order to demonstrate this point, the following section will describe how each of the three sets of arguments analytically constructed above as three different programs of action, meet different forms of resistance, and how they seek to fend off these anti-programs.

\section{Resistance to the argument of being ahead of the pack}

One type of resistance to overcome is related to disappointed accounts of technical shortcomings, which result in low quality aesthetics. When users talk about moments where SL shows its

\footnotetext{
${ }^{22}$ Interview (5 Feb 2010) with Bob Ketner of The Tech Virtual @ [https://blogs.secondlife.com/community/learninginworld/blog/2010/02/05/prototyping-real-world-museumexhibits-in-second-life-at-the-tech. Accessed 29 Mar 2010

${ }^{23}$ Official UWA blog: http://uwainsl.blogspot.com/ Accessed 12 Apr. 2010
} 
technical limitations, it becomes hard to make the ahead of the pack argument. For instance, SL had been used to produce renderings of a public construction project, but the dimensions of the rendering posed problems. The client had constructed:

... a giant billboard approximately 60 feet tall and 400 feet long, awaiting renderings of the proposed project. The resolution of SL renderings on a laptop screen is one thing, but blown up to that scale is quite another. It remains to be seen whether this will have to be rebuilt in $3 d$ max in order to produce sufficient quality renderings" 24

Another obstacle to argue with is advanced users' accounts about catching up with the fast development of newer social media and more advanced software. In the above, we noted that various actors used the 'ahead of the pack argument' for being present in Second Life. Of course, these types of actors are fast to move on. Developer of virtual property (and the first dollar millionaire in SL) Anshe Chung Studios articulated the selling point in the following way:

"Your first step into the Metaverse, an immediate virtual world presence, is an unequivocal message to your customers. [...] To be a leader of change (not merely a witness to change), you have to evolve with the virtual community at a pace that makes even the Web look static. Such a commitment to stay ahead of the pack [... $]^{\prime \prime 25}$

However, although still operating in Second Life, since early 2007 Anshe Chung Studios has functioned as a proponent of other virtual worlds (e.g., IMVU, Frenzoo) of no interest for designers/architects employing 3D-modelling professionally. It also seems to be the case that if you want to make an "ahead of the pack"-program by choosing a new media communicationsplatform, FaceBook and Twitter are the ones you go for in 2011. Choosing Second Life was useful as a communicative positioning strategy roughly from Sep. 2006 to Feb. 2008, but then other technologies took the place as the signifier of technological frontrunners. Presently, we see promotional talk like this, in a hotel chain which was earlier among the first to move into SL: "Sync up and link up with other Aloft fans. Check out our blog for the latest a-list info, connect with us on Facebook, challenge your friends to a game of pool, grab our cool new Style at a steal video widget, follow us on Twitter and much more ${ }^{\prime 26}$.

Accounts of technical challenges, and challenges from other communication platforms obviously make it increasingly difficult to argue that SL is the meeting point for architects and their clients if they want to signal that they are at the forefront of technological developments.

\section{Resistance to the revelation argument}

The program of revelation also runs into different forms of resistance that serve as anti-programs. In architectural education, for example, some have experimented with letting students design prototypes of houses, and describe resistance both as a matter of technologically challenged users, and as a matter of change resistant users. As a teacher expressed it, "Some students begged

\footnotetext{
${ }^{24}$ http://archvirtual.com/?p=1153. Accessed 30 Mar 2010

25 http://acs.anshechung.com/ Accessed 30 Mar 2010

${ }^{26}$ http://www.starwoodhotels.com/alofthotels/newsevents/index.html. Accessed 30 Mar 2010
} 
for the option to build (physical) models instead, but I did NOT relent - and guess what... they discovered it wasn't so bad!" ${ }^{27}$ The same teacher experienced that a student's spouse would not allow that Second Life be used on their home computer, since it was perceived as being just a video game. And finally, colleagues conceived of SL as an extra work burden, and did not immediately appreciate that it has something extra to offer:

A lot of my colleagues [...] are overwhelmed by normal changes in CAD - our eventual migration to BIM for instance, that they would love to know more about it, but they have too much other on their plate. But I explain that this is not like BIM. BIM is replacing in a major way our existing way of doing work, whereas virtual worlds are going to be something adding a new dimension - something different, not replacing not just a drafting or working drawing tool. It will redefine the role of the client, as you well know with Wikitecture."

This is an example of how users do not support the argument that Virtual Worlds Architecture is a helpful tool, but rather produces counterarguments which position it as a complicated technical matter, that just makes it even more complicated for them to do their job. Actors express how argumentation and convincing is needed, very much because an experience of complexity overshadows the experience of a clearer understanding. There is also an issue of the distribution of burdens and benefits. Architects and designers, who are not frontrunners within the field of Virtual Worlds Architecture, will see themselves as having to bear the whole burden of complexity and learning how to use a new technological tool, while it is primarily the end-users of architecture who is supposed to benefit in the revelation-program. What was clearly the selling point of the innovation in this program, is turned into a problem, and the potential users also change status and become ignorant and conservative. The selling point of Virtual Worlds Architecture is sometimes hard to sell. In the words of a designer:

"Having spent over a year plus creating primary architectural structures in a virtual reality, I was recently asked is it really real what I do? It's only on a screen, why would anyone pay you for what you do? They can only see it on a screen they can't touch it or feel it?"28

A related issue is the problem - for architects - of articulating low expectations in relation to future clients' enthusiasm and skill. In the words of an architect who is inexperienced with SL:

I am interested in exploring the possibility of presenting designs in a virtual world such as SL. I work with several CAD programs including SketchUp and would like to know if there is any provision for importing $d x f$ or $3 d s$ models into SL. I would hate to think that I would have to recreate the entire model using SL's building system. I also can't see some of my clients going through the process of getting SL memberships,

\footnotetext{
${ }^{27}$ http://archvirtual.com/?p=1187 (Interview with Professor L.C. Weaverling of The Delaware Technical \& Community College)

${ }^{28}$ http://primpushers.blogspot.com/2010/04/architecture-in-virtual-reality.html, accessed 11.5.2010
} 
logging in, and learning the interface just to see their project. "Can't you send it on a $C D ?^{\prime \prime 29}$

The architect himself is trying to learn about the potentials of $\mathrm{SL}$, in particular for mesh imports, and blogs about this on the aloft site. In principle, he is open and curious about it, but after a long response explaining what SL offers, he returns with a concluding comment, that SL so far mostly offers extra work to both architects and clients.

If we see the above as an anti-program, we see how this is part of the conditions of innovation communication, which makes it difficult to uphold the idea of a quick technological fix to problems of understanding space. These problems become translated into a new set of problems of dealing with the technology itself. Hence, articulations from this anti-program seriously disturb the programs described above.

\section{Resistance to the open innovation argument}

The open innovation argument runs into two types of resistance - besides the technical difficulties - namely an idea of actors' inabilities to take up the innovation and give it a life after the architect leaves the project, and stories about decision-makers' unwillingness to take seriously the results of co-creation and open innovation.

One type resistance to the argument of open innovation stems from stories about the problems of taking up and using virtual worlds once architects exit a given project. It shows that constructing users and convincing them that virtual worlds have something to offer to user-driven innovation do not make up the only challenges for architects who try to introduce such communication platforms. It is argued that they have to be taken up and used by others, also when the architect steps back. Only in this way, SL and other platforms can reach their potentials as something beyond a design tool:

Perhaps the ultimate test is not just how useful [SL] is for the architect as a design tool, but will it have a life beyond? The dream is for the client to use the final build for promoting the project and leasing tenant space [...] Right now, we are simply using it as a design tool. As such, we are constantly making changes, leaving behind more of a $3 d$ sketch than a presentable product. If it does have a life beyond the design process, it will probably have to be rebuilt - a major concern. ${ }^{30}$

So it is not enough that the architect plays around with virtual worlds, they also have to be appropriated, and this is constructed as a challenge for Virtual Worlds Architecture. Architects point out that $\mathrm{SL}$ is not merely a representational gimmick, useful in the design phase, but can be integrated in business strategies of clients after the construction of the building. For instance, David Denton, the architect behind the shopping mall in Cairo, had the ambition of delivering a 3D-model that his client could then use as promotional material to his clients (i.e., the shop-

\footnotetext{
${ }^{29} \mathrm{http} / / /$ www.virtualaloft.com/2006/08/on importing 3d models into se.php Accessed 18.5.2010

${ }^{30}$ http://archvirtual.com/?p=1153. Accessed 29 Mar 2010
} 
owners who are to rent lots in the mall). This however, did not happen as the owner of the building met resistance to the use of Second Life in his social network.

As an example of the other type of resistance, the Landing Lights project ran into problems in relation to the Community Board which had put the project in motion. This became constructed as a clash between virtual worlds and real life. As reported in New York Times, the project was

...intended to solicit neighborhood input on how the park should be improved. And though the software is still being fine-tuned, [Thomas Lowenhaupt, chairman of Community Board 3's Technology Advisory Committee] said, "in an ideal world, everyone would be able to save their favorites, and then everyone could vote, 'American Idol'-style, for their favorite park design." [...] Mr. Lowenhaupt has run up against some real-world obstacles. He had hoped to set up a special Landing Lights Park coordinating committee to smooth the process of designing the new park, but at a meeting on May 18, the community board rejected his proposal. [...] So, like many cyber-innovators before him, Mr. Lowenhaupt finds himself confronting a frustrating truth. "The difficult part," he said, "is the convergence of the real and virtual worlds ${ }^{31}$

The process can be interpreted as an instance of initial fascination with the possibilities of cocreation and open innovation afforded by SL, which becomes replaced with top-down steering when virtual projects have to be realized physically. We can identify a type of argument saying that the technical possibilities of inclusion may allow for creative bottom-up processes, but that they often go in 'wrong' directions. As such, these experiments with user-involvement through virtual worlds suffer from the same problems of allowing citizen voices to have an impact, as for instance engagement exercises in science and technology development more broadly (Hagendijk et al. 2005; Wynne 2001).

\section{Concluding discussion}

In this paper, we have chosen to expand the analytical focus beyond Virtual Worlds as sites for social and cultural innovation, to examine innovation communication processes which take place both in and around such sites. Here, the innovative aspect lies in the re-articulation of the potentials of Virtual Worlds. Rather than seeing Virtual Worlds as sites for social and cultural innovation, we have examined how actors try to sell them as such. From our perspective, 'selling' is not an activity which occurs once an innovation is a matter of fact, but is intertwined with processes of innovation. The empirical material showed us how selling points are not given, but have to be constructed and sold, both discursively and economically. Our analyses indicated what is implied in the central arguments for using SL (and other virtual worlds) for purposes of communicating about architecture. With each argument come different selling points, shifting configurations of users, and shifting implications for the production of new markets. We want to emphasize that such arguments are not put forward by particular users, but function as discursive resources that different actors may draw upon in combination. So for instance the ahead of the pack argument and co-creation argument may very well be drawn upon simultaneously, hence in practice the configuration and persuasion of users produce a set of circulating discourses which

\footnotetext{
${ }^{31}$ http://www.nytimes.com/2006/06/18/nyregion/thecity/18wire.html. Accessed 31 Mar 2010
} 
form an important part of the backdrop of the wider adaption of the innovation: the technology should be adopted, because the tech savvy users rightfully want it, and they in turn, because they are tech-savvy, can also contribute creatively to the innovation process. We propose that the success of innovation is heavily dependent on such arguments about technology, users' demands, democracy, and creativity because they serve as rhetorical ways of generating support for the particular program of action favored by the VWA entrepreneur.

We do not consider the arguments and types of resistance unique to Virtual Worlds Architecture or Second Life, but see them as resources drawn upon in other instances of marketing or strategic communication as well. Hence, it can be argued that what we witness in this material are converging business and innovation rhetorical patterns, which contribute to the blurring of boundaries between the inside and outside of Virtual Worlds.

On a theoretical level, the analyses have opened up for a discussion of ANTs concepts of programs and anti-programs. We believe that the focus on innovation communication in relation to technologies in the making have created a complex picture of interweaving arguments in the relation to the selling of Virtual Worlds Architecture. This leads us to suggest that we need to soften ANTs often quite sharp analytical division between programs and anti-programs (standing as two opposing sides gradually losing or gaining power) to see them as made up by elements that can switch sides and appear in new combinations throughout innovation processes.

\section{Interpretative flexibility and innovation communication}

Given our analytical focus, we are not talking about Virtual Worlds Architecture as an innovation in singular. Rather, the type of innovation we deal with here is the production of new combinations of more traditional communication processes and ones supported by Virtual Worlds. With this complexity also comes a variety of possible programs of action linked to creating selling points and configuring users - so as to stabilize the innovation in the future. We have mentioned how one perspective on interpretative flexibility is that it increases wider adaption or appropriation of an innovation. This suggestion follows the lines of thought of Woolgar (1991), as he has argued for looking at technologies as texts open to various interpretations. From this perspective, entrepreneurs of Virtual Worlds Architecture should be happy about the various conflicting programs of action, because they invite a diverse set of future users to connect to them. However, as we have seen, the large interpretative flexibility also leads to problems, because the different programs serve as anti-programs to each other. The revelation argument and the ahead of the pack argument run the risk of being directly in conflict with each other, which is the case when we look at the resistance each of them meet. Resistance to the revelation argument stems from the fact that Virtual Worlds are technically complex and difficult new media platform to work with. In this form of communication, any talk about tech savvy audiences who demand a constant adoption of new technology seems to make the resistance more well-founded. And likewise, communication towards tech savvy audiences in their capacity as front runners cannot include statements directed towards late adopters and skeptical users. Communicating about the simplicity of the technology might be exactly what drives the tech savvy audiences in the ahead of the pack argument away. On the basis of such analytical observations, we propose that empirical analyses of innovation communication offer a fruitful inroad to unpacking the inherent problems of interpretative flexibility of emergent technical innovations. The interpretative flexibility lies not 
only in the different uses a given technology can be put to, or the different users inscribed into it, but also in the discourses and arguments which are intertwined with processes of innovation.

We also propose that attempts to delimit the interpretative flexibility of emerging innovations make up the strategic dimension of innovation communication. For innovators or entrepreneurs, recognition of the competing technological and discursive programs of action could be a valuable input to strategies of delimiting interpretative flexibility. In relation to Virtual Worlds Architecture, it seems necessary for architects to provide for particular readings of them in a strategic way. Importantly, strategic innovation communication should be about delimiting interpretative options, rather than determining them.

\section{Suggestions for further research}

On the basis of this paper, it is possible to point to at least two obvious lines of further research. One would be an examination of how Virtual Worlds Architecture is used and negotiated in practice, while the other would be a study of how Virtual Worlds and other technologies increasingly converge in mixed technologies solutions. Such a study could also pose the question of how the transition from singular technologies of play into communication platforms for professional usage is interwoven with processes of economization.

The analysis of arguments for using SL as a communication platform for architecture has pointed at possible problems of enrolling actors in practice. Further studies could follow the processes of actually enrolling actors in concrete projects. This could lead to insights about the challenges of introducing an innovation which both caters to users with supposedly high expectations in relation to professionalism, immersion, and participation and users supposedly unable to see through SL's technical and aesthetic limitations and unable to understand the specificity of what this technology affords. Since architects' customers often have limited practical experience with advanced technologies, the use of innovative communication formats in concrete projects seems to result in ongoing negotiations between innovative architects and customers about the rationale and advantages of virtual worlds. Given the complexity of Virtual Worlds Architecture as an innovation in the making, we cannot count on users to reach a final state of 'skilled usage'. The ad hoc character of construction projects has enormous significance for this question. Most users never get the chance to acquire competence. Seeing how users become dependent on the VW architect clearly poses serious questions to the idea of using object-based virtual environments to empower the user in the design process. The question is whether this is a passing phase that will be over once the users become technically more skilled in virtual environments, or whether the asymmetry is a more fundamental aspect of innovation within communication forms such as virtual environments. A study of such dilemmas in practice could contribute to discussions of ideals of democratic communication in relation to new media technologies.

In the analyses above, we have mostly focused on arguments for using SL. Our analytical focus has restricted us from including numerous references to mixed technologies solutions, but future studies could follow the leads of various actors, who show awareness of the fact that it will become easier to import architectural CAD and BIM models in the months and years ahead ${ }^{32}$, and - more generally - integrate various technologies to communicate about architecture. Mixed

\footnotetext{
${ }^{32}$ http://blog.pradprathivi.com/2010/01/30/sl-mesh-imports-will-it-backfire/ and http://www.virtualaloft.com/2006/08/on importing 3d models into se.php. Accessed 31 March 2010
} 
technology communication platforms offer a new set of promises of grand solutions to solving information and communication problems in architecture. They are already in use, such as in the Cairo shopping mall project which aims at integrating 3DMax, Autocad, Maya, and Sketchup with Second Life ${ }^{33}$. It is also the case for the numerous local community engagement projects that they integrate virtual worlds with other means of expression - as in the Landing Lights project mentioned above. Crescendo owner Jon Brouchoud, who is very active in commenting on the various architectural projects using a mixture of virtual worlds and other platforms, comments on this development in connection to a particular project:

What I find most interesting is their blended use of Second Life, a web interface and a Google maps page. In this case, residents can use Second Life to explore the virtual rendition of the neighborhood, but they need not learn the in-world building tools to express design ideas. Instead, they use an interactive web site that enables them to drag and drop icons, such as building elements, paving, landscaping, and more. They then 'publish' the map they've created, and it appears in the Second Life 'gallery' space." 34

In contrast to the visions about Virtual Worlds Architecture analyzed in this paper, these visions of mixed technology solutions have fewer references to future users, possibly because they are implicitly conceived of as a restricted, exclusive crowd of tech savvy first movers. And given the very emergent state of mixed technology solutions, there is still very little to be sold. But future studies within this area should not neglect what is probably the only viable path of innovation in relation to advanced ICTs in architecture.

In such studies, it could be emphasized how innovation processes are not only intertwined with user configuration and innovation communication, but also with process of marketization (Çalışkan \& Callon 2009, Callon \& Caliskan, Work in progress). From the perspective of Çalışkan and Callon, marketization is a laborious process that consists of the assembly of actions, devices, materialities and economic knowledges. Compared to the framework of Çalışkan and Callon, this paper has placed particular emphasis on the role of communication in creating markets. It has done so by pointing to the fact that marketization happens at several levels in the cases of SL architecture. Ultimately, the architects are trying to market the idea of the physical building as a user-involved and democratized project through the use of innovative communication in SL. However, in order to do this marketization, the architects first have to market the idea of using SL as a communication platform. What might have looked as an innovative means to another end turns up to be an object for marketization itself. But to return to the framework of Çalışkan and Callon, the concepts of marketization or economization could direct the attention to the processes of turning social media designed to further social or cultural innovation, or conventionally coupled with passion or play, into products to be used innovatively in professional practices.

\footnotetext{
${ }^{33}$ http://reflectionsegypt.ning.com/. Accessed 29 Mar 2010

34 http://archvirtual.com/?p=1892. Accessed 1 Apr 2010
} 


\section{References}

Akrich, M. (1995) 'User representations: Practices, Methods and Sociology' in Rip, Misa \& Schot (eds) Managing Technology in Society, pp. 167-184. London and New York: Pinter Publishers

Akrich, M. (1994) 'The De-Scription of Technical Objects' in W. E. Bijker \& J. Law (eds), Shaping Technology/Building Society, Studies in Sociotechnical Change, pp. 205-224. London: The MIT Press

Brown, N. \& M. Michael (2003) 'A sociology of expectations: Retrospecting prospects and prospecting retrospects', Technology Analysis \& Strategic Management, vol. 15 (1): pp. 3-18.

Brown, N., B. Rappert \& A. Webster (2000) 'Introducing contested futures: from Looking into the future to looking at the future' in N. Brown, B. Rappert, \& A. Webster (eds.) Contested Futures: A sociology of prospective techno-science, pp. 3-20. Aldershot: Ashgate

Çalışkan, K. \& M. Callon (2009) 'Economization, Part 1: Shifting Attention from the Economy towards processes of Economization', Economy and Society, Vol 38: pp. 369-398.

Callon, M. \& K. Caliskan (Work In Progress), 'Economization: New Directions in the Social Studies of the Market'

Collingridge, D. (1980) The Social Control of Technology, New York: St. Martin's Press.

Ewenstein, B. \& J. Whyte (2009) 'Knowledge Practices in Design: The Role of Visual Representations as 'Epistemic Objects', Organization Studies. Vol. 30: pp. 7-30

Gänshirt, C. (2007) Tools For Ideas: An Introduction to Architectural Design, Basel: Birkheuser

Grint, K. \& S. Woolgar (1997) The Machine at Work: Technology, Work and Organisation, Cambridge: Polity

Hagendijk, R., P. Healey, M. Horst \& A. Irwin (2005) STAGE: Science, Technology and Governance in Europe: Challenges of Public Engagement, (HPSE-CT2001-50003), European Commission.

Horst, M. (2010) 'Collective Closure? Public debate as the solution to controversies about science and technology', Acta Sociologica. Vol. 53 (3): pp. 195-211.

Hyysalo, Sampsaa (2006) 'Representations of Use and Practice-Bound Imaginaries in Automating the Safety of the Elderly', Social Studies of Science. Vol. 36 (4): pp. 599-626.

Latour, B. (1986) 'The powers of association' in J. Law (ed.) Powers, Action and Belief - A new Sociology of Knowledge? pp. 264-280. London: Routledge

Latour, B. (1987) Science in Action - How to Follow Scientists and Engineers through Society, Cambridge: Harvard University Press 
Law, J. (ed) (1991) A sociology of monsters: Essays on power, technology and domination, London: Routledge

Law, J. (1986) Power, Action and Belief, London: Routledge

Lindsay, C. (2003) 'From The Shadows: Users as Designers, Producers, Marketers, Distributors, and Technical support' in N. Oudshoorn \& T. Pinch (eds.) How Users Matter: The Co-Construction of Users and Technology, pp. 29-50. Cambridge: The MIT Press

Oudshoorn, N, E. Rommes \& M. Stienstra (2004) 'Configuring the user as everybody: gender and design cultures in information and communication technologies', Science, Technology \& Human Values. Vol. 29 (1): pp. 30-63

Oudshoorn, N. \& T. J. Pinch (2005) How Users Matter: The Co-Construction of Users and Technology. Cambridge: The MIT Press

Oudshoorn, N. (2003) 'Clinical Trials as a Cultural Niche in Which to Configure the Gender Identities of Users: The Case of Male Contraceptive Development' in N. Oudshoorn \& T. Pinch (eds.) How Users Matter: The Co-Construction of Users and Technology, pp. 209-227. Cambridge: The MIT Press

Pallasmaa, J. (ed.) (2005) Encounters. Architectural Essays, Helsinki: Rakennustieto

Perelman, C. \& L. Olbrechts-Tyteca (1969) The New Rhetoric. A Treatise on Argumentation. London: University of Notre Dame Press

Pinch, T. (2003) 'Giving Birth to New Users: How the Minimoog Was Sold to Rock and Roll' in N. Oudshoorn \& T. Pinch (eds.) How Users Matter: The Co-Construction of Users and Technology, pp. 247-270. Cambridge: The MIT Press

Pinch, T. J. \& W. E. Bijker (1984) 'The social Construction of facts and artefacts: or how the sociology of science and the sociology of technology might benefit each other', Social Studies of Science. Vol. 14, pp. 399-441

Plesner, U. (2010) 'Information versus immersion: multidirectionality in the development of integrated ICTs in architecture'. Paper presented at International Communication Association, Singapore, June

Plesner, U. \& M. Horst (2010) 'Monstrous Models or Virtual Buildings: The non-standardization of communication technologies in architectural work'. Paper presented at the conference of the Society for the Social Studies of Science, Tokyo, August

Rice, C. (2007) The Emergence of the Interior: Architecture, Modernity, Domesticity, London Routledge

Rogers, E. (1995) Diffusion of Innovation, New York, The Free Press 
Schot, J. \& A. A. de la Bruhéze (2003) 'The Mediated Design of Products, Consumption, and Consumers in the Twentieth Century' in N. Oudshoorn \& T. Pinch (eds.) How Users Matter: The CoConstruction of Users and Technology, pp. 229-245. Cambridge: The MIT Press

van Kammen, J. (2003) 'Who Represents the Users? Critical Encounters between Women's Health Advocates and Scientists in Contraceptive R\&D' in N. Oudshoorn \& T. Pinch (eds.) How Users Matter: The Co-Construction of Users and Technology, pp. 151-171. Cambridge: The MIT Press

Van Lente, H. \& A. Rip (1998) Expectations in Technological Developments: An example of prospective structures to be filled in by agency. Getting new technologies together. Studies in making sociotechnical order, Berlin: Walter De Gruyter

Van Lente, H. (1993) Promising Technology: The Dynamics of Expectations in Technological Developments, PhD-thesis, University of Twente.

Von Hippel, E. (2005) Democratizing Innovation, Cambridge: The MIT Press

Wilkie, A. \& M. Michael (2009) 'Expectation and Mobilisation: Enacting Future Users', Science Technology \& Human Values. Vol. 34, pp. 502-522

Woolgar, S. (1991) 'Configuring the user: the case of usability trials' in J. Law (ed.) A sociology of monsters: Essays on power, technology and domination, pp. 58-102. London: Routledge

Wynne, B. (2001) 'Creating public alienation: Expert cultures of risk and ethics on GMOs', Science as Culture. Vol. 10 (4), pp. 445-481

Yaneva, A. (2009) The Making of a Building - A Pragmatist Approach to Architecture, Oxford: Peter Lang 
Ursula Plesner, PhD, assistant professor, Department of Organization, Copenhagen Business School

Ursula Plesner is an assistant professor at the Department of Organization, Copenhagen Business School. Her research focuses on the ways in which new Information and Communication Technologies impact processes of organizing work relations and communication flows. She is interested in the role of discourses and expectations in innovation processes, and draws on the sociology of science and technology to make sense of the complex interplay between technology, discourses and social organization. She has published in Public Understanding of Science, Qualitative Inquiry and Journalism - Theory, Practice and Criticism

E-mail: up.ioa@cbs.dk

\section{Mailing address:}

Ursula Plesner

Department of Organization, CBS

Kilevej 14A

2000 Frederiksberg

Denmark

Phone: (+45) 38152810

Fax: (+45) 38152828

Maja Horst is associate professor at Department of Organization, Copenhagen Business School in Denmark, where she conducts research within the area of Science and Technology Studies. She focuses particularly on research communication, public understanding of science and the organization and management of research. Among other places, she has published in Social Studies of Science; Science, Technology and Human Values; Public Understanding of Science; and Science and Public Policy. 